\title{
Comprensión y explicación en antropología
}

\author{
José Vegas Pozo \\ thania699@hotmail.com \\ Departamento de Antropología. UNMSM
}

\begin{abstract}
Resumen
Mi escrito propone un acercamiento a la Antropología Euroamericana y una especificación de la temática de nuestro universo sociocultural. Asimismo, una conceptualización de la investigación etnográfica.
\end{abstract}

Palabras clave: Antropología euroamericana, Universo sociocultural peruano, Etnografía.

\begin{abstract}
My writing proposes an approach to the Anthropology Europe American and to the specification of the universe social-cultural thematic. Also, a conception of the investigation ethnography.
\end{abstract}

Keywords: Anthropology Europe American, Universe Social-Cultural Peruvian, Ethnography.

Como lo he señalado en un documento anterior ${ }^{1}$, parto de las premisas en que el manejo articulado de la Etnografía y la comparación, así como la investigación científica, tanto en antropología como en las otras ciencias sociales, constituyen las herramientas básicas para la producción del conocimiento antropológico.

La Antropología y las otras ciencias sociales pretenden dar cuenta de lo social en tanto se explica por sí misma, como una dimensión externa a la conciencia de los individuos. Buscan la existencia de regularidades que caracterizan a los fenómenos y procesos sociales para explicarlos y manejar una perspectiva de análisis para comprender la totalidad social, tanto en su estructuración actual como en la dinámica de su proceso histórico. Del estudio de la sociedad como totalidad se deriva el alto nivel de abstracción, por eso los fenómenos sociales son totales.

En suma, el objeto del conocimiento social no es solo la sociedad, sino todo ese conjunto de relaciones e interacciones de los hombres entre sí y con la sociedad institucional, la cultura y la naturaleza.

1 VEGAS POZO, José (2007). Reforma Curricular de Antropología. 
Mi escrito se propone un acercamiento a la Antropología Euroamericana y una especificación de la problemática del objeto de estudio de nuestro universo sociocultural, en primer lugar; seguidamente, una conceptualización de la investigación etnográfica, el cambio permanente de sus métodos y técnicas de investigación en la acumulación e interpretación del material empírico.

\section{La perspectiva histórica}

En la división internacional del trabajo intelectual en el campo de las ciencias sociales, a la Antropología le correspondió la investigación de las "otras culturas", de los pueblos "primitivos", "tradicionales", de las sociedades diferentes al mundo occidental; es decir, el estudio del universo colonial de las potencias de Europa y Norteamérica, para conocerlos y dominarlos mejor. Estas relaciones de dominación y explotación las expresa con claridad el texto de Kathleen Goyugh: Antropología e Imperialismo (1970).

Los países europeos crearon sus propias disciplinas para el conocimiento de sus estructuras y el tratamiento de sus problemas sociales, como la economía política (Smith - Ricardo), la sociología, la historia, etc.

Como señala el antropólogo norteamericano Marvin Harris, en uno de sus textos:

"...la antropología es el estudio de la humanidad, de los pueblos antiguos y modernos y de sus estilos de vida. Las diferentes ramas de la antropología se centran en distintos aspectos de la experiencia humana. Algunas de ellas estudian cómo nuestra especie evolucionó. Otras analizan como llegamos a poseer la aptitud para el lenguaje...otras, por último, se ocupan de las tradiciones del pensamiento y la conducta humanas de la forma en que evolucionaron y se diversificaron las culturas antiguas y de cómo y porqué cambian o permanecen inmutables las culturas modernas". ${ }^{2}$

Como podemos constatar desde la perspectiva de Harris, es decir, del materialismo cultural, el objeto de estudio de la Antropología cambia sustancialmente, $\mathrm{y}$, como es notorio, no hace ninguna referencia a las relaciones de explotación y dominación existentes, aún ahora, entre los países capitalistas altamente industrializados y los países del Tercer Mundo, mal llamados "subdesarrollados".

Mi afirmación anterior la confirma nada menos que Noam Chomsky, experto lingüista y analista político internacional estadounidense, quien en uno de sus libros del 2004 precisa:

"el objetivo de la gran estrategia imperial es prevenir cualquier desafío al poder, posición y prestigio de Estados Unidos...un corolario crucial es el de la vigilancia para bloquear cualquier intento por un desarrollo independiente que pueda convertirse en un "virus que afecte a otros", según la terminología de los estrategas".

En este libro, Chomsky expone y analiza la actual estrategia estadounidense de dominación global y explica cómo las acciones de su gobierno significan un grave riesgo para la estabilidad y la seguridad mundial, con consecuencias potencialmente catastróficas.

Desde nuestro punto de vista, la Antropología es el estudio del Homo Sapiens y de su cultura, es decir, la gran diversidad de modos de vida, de comportamientos sociales de los distintos grupos humanos existentes en diferentes contextos históricos.

También es necesario relevar que la Antropología, en efecto, estudia los pueblos antiguos y modernos y no se limita más a las “culturas primitivas", no occidentales, sino que también estudia diversos problemas como las colonias de inmigrantes, las minorías étnicas marginadas, las desigualdades socioeconómicas, el calentamiento global, la pobreza, etc., en los mismos países de Europa y Norteamérica.

2 HARRIS, Marvin (1981). Introducción a la Antropología General. Madrid: Alianza Editorial S.A.

3 CHOMSKY, Noam (2004). Hegemonía o supervivencia. La estrategia imperialista de Estados Unidos. México: Editorial B. 
La Antropología no tiene fronteras, a semejanza del conjunto de las Ciencias Sociales. La Antropología y las ciencias, en general, cambian, porque la realidad sociocultural y socioeconómica también cambian, más aún en estos tiempos de crisis y globalización vertical, imperial y uniformizadora, según el "modelo de desarrollo" impuesto, atentando contra la autonomía y soberanía de los países tercermundistas.

Asimismo, es importante destacar que la antropología enfatiza en el análisis de la cultura, de las tradiciones socialmente aprendidas del pensamiento y la conducta humanas y la función de la Etnografía de describir e interpretar a nuestros contemporáneos "primitivos".

Sobre esta base, con la comparación de descripciones e interpretaciones, se formulan hipótesis y teorías para comprender y explicar las causas de las similitudes y diferencias. El objetivo es construir una antropología causal, explicativa y generalizante.

Pero el estudio del Homo Sapiens y la cultura que se produce en sociedad, se realiza desde enfoques diferentes.

1. La Antropología Cultural con Franz Boas en Estados Unidos, que estudia la cultura como modo de ser y actuar propio del grupo humano.

2. La Antropología Social con Bronislaw Malinowski y Alfred Radcliffe-Brown en Inglaterra, que analiza la estructura social de los pueblos primitivos.

3. La Etnología de Marcel Mauss en Francia, que también estudia la organización social y sus instituciones, pero con una connotación filosófica en la comprensión de la vida social.

Constituyen las escuelas nacionales en Estados Unidos, Inglaterra y Francia que influyen en el proceso de formación de la antropología en el Perú, especialmente la Antropología Cultural en las primeras décadas.

Igualmente, a partir del siglo XIX se desarrollan en Antropología, las teorías sobre la cultura como el evolucionismo, en el siglo XX, darwinismo social, el evolucionismo marxista, el difusionismo, el neoevolucionismo, la antropología marxista, el materialismo cultural, el estructuralismo, la antropología simbolista, la antropología posmoderna y la antropología y ecología.

\section{La problemática de la Antropología en el Perú}

En esta sección, intento una aproximación a la temática actual de la antropología en el Perú. Desde un primer momento, se propone dar cuenta de la especificidad de la formación social peruana en su devenir histórico, es decir, relacionar Antropología y sociedad, y para ello será imprescindible el análisis comparativo y las referencias a otros contextos socioculturales. La Antropología surge como un intento de señalar y estudiar los elementos culturales e institucionales autóctonos de los sectores tradicionales y su articulación con la sociedad.

Históricamente, la Antropología como carrera académica universitaria, fue creada en mayo de 1946 por el distinguido y esclarecido historiador Luis Eduardo Valcárcel Vizcarra; y se formó el Instituto de Etnología y Arqueología, en la entonces Facultad de Letras.

En su proceso de formación tiene como precursores los escritos de cronistas, viajeros y misioneros. La Antropología como campo de conocimiento nace cuando occidente se contacta con el Nuevo Mundo y los españoles conquistan, colonizan y cristianizan a las sociedades indígenas, especialmente a las altas culturas Azteca, Maya e Inca. Cortan su desarrollo autónomo e histórico. Autonomía y soberanía que es necesario reestructurar ahora.

Esta disciplina recoge su información empírica, sobre todo, por medio de la observación participante y la analiza comparativamente. Utiliza la Etnografía y la Etnología. Es la tradición científica occidental la que crea el aparato conceptual para describir y explicar 
los hechos y procesos sociales, que nosotros debemos reinterpretar, de acuerdo a nuestras particularidades socioculturales.

También señaló que desde fines del siglo XIX y durante la primera mitad del siglo $\mathrm{XX}$, surge el indigenismo como reivindicación del "indio actual" y no solo del histórico $\mathrm{y}$ de su incorporación como base fundamental de la "comunidad imaginada" peruana. El indigenismo jugó un papel importante en el proceso de constitución de la Antropología, ésta es hija del indigenismo.

Ahora bien, para referirnos a la temática actual parto de la caracterización de la sociedad peruana como multicultural y pluriétnica, de desarrollo económico desigual y dependiente.

La Antropología, como lo señalan varios autores ${ }^{4}$, es una disciplina global, comparativa y multidimensional. Es una característica fundamental que la diferencia de las otras ciencias sociales. Es una disciplina globalizante integrativa, multidimensional, que se interesa por todas las formas de conocimiento y comportamiento de los diferentes grupos humanos.

Puedo precisar que, desde una perspectiva de conjunto, la antropología estudia, analiza e interrelaciona áreas como las comunidades nativas amazónicas, étnicoculturales y sus conflictos; las comunidades campesinas andinas; el campesinado y su diferenciación interna; la problemática de las colonias urbanas, como la de los conos, descendientes en gran parte de los inmigrantes del interior del país; la sociedad nacional, como totalidad social.

Se estudian sus características socioculturales; sus roles, estatus y acciones sociales; sus criterios juicios y conocimientos que los individuos y grupos sociales asumen en el proceso de socialización; las motivaciones, creencias y valores que impulsan más directamente a la acción social y que constituyen su subjetividad; las instituciones sociales que integran el conjunto de la sociedad organizada; las normas y pautas de comportamiento originadas en la vida social; su variabilidad, el cambio que es una propiedad fundamental y las distintas y múltiples obras culturales.

Además, es necesario comprender la ampliación de su temática de estudio e investigación, como los estudios sobre las relaciones interétnicas, etnicidad e identidad, de género, las redes sociales, las migraciones, la interculturalidad, la religiosidad popular, las organizaciones vecinales urbanas, la globalización, etc.

La realidad sociocultural, socioeconómica y política cambia permanentemente en este mundo globalizado, en temas fundamentales como la tecnología, la producción, la organización social, el desarrollo, la cultura, la religiosidad, la biotecnología, que genera otro tipo de desigualdades sociales, y que se dan no solo en el Perú y América Latina, sino en todo el planeta. Frente a esta problemática dinámica, ¿nuestra antropología está en condiciones de enfrentarla y explicarla? Creo que no.

Es necesario construir una antropología para explicar la diversidad étnicocultural desde una perspectiva intercultural. Otros tienen que ser nuestros paradigmas. Como es lógico la Antropología al igual que las otras ciencias sociales, tiene que poner a prueba sus teorías, a partir de su acercamiento sistemático y permanente a la realidad sociocultural, utilizando la investigación etnográfica y el método comparativo.

En suma, laAntropología debe propender a que sus estudiantes conozcan sustantivamente determinadas áreas socioculturales; la capacidad de diagnóstico de las condiciones de vida de distintos grupos humanos; programar alternativas de cambio y desarrollo, tomando en cuenta los conocimientos locales de la población involucrada; conocer las características

4 SILVA SANTISTEBAN, Fernando (1998). Antropología. Conceptos y nociones generales. Lima: Universidad de Lima, Fondo de Cultura Económica. 
y dinámica de nuestra realidad sociocultural y formular las propuestas necesarias y, finalmente, la capacidad de elaborar proyectos de investigación científica.

\section{Etnografía y Comparación}

\section{La Investigación Intercultural en Antropología}

La Etnografía es el estudio descriptivo ("graphos") de la cultura ("ethnos") de una comunidad. En la perspectiva de Aguirre: "la etnografía es el estudio descriptivo de la cultura de una comunidad o de algunos de sus aspectos fundamentales bajo la perspectiva de comprensión global de la misma" ". ${ }^{\text {se }}$. Su carácter es descriptivo, el que era patente en las monografías etnográficas; se diferencia de la Etnología, que resulta del análisis comparativo entre varias culturas con fines teóricos. Etnografía y Etnología van de la mano.

En la etnografía, la dimensión descriptiva no es obstáculo para el análisis de la cultura en términos de identidad, totalidad, eficacia, por lo que estamos en condiciones de conocer la identidad étnica de la comunidad estudiada, de comprender la cultura como un todo orgánico y de verificar cómo esa cultura está viva y es eficaz en la solución de los problemas de la comunidad.

La Etnografía es una estrategia distintiva de la Antropología.

Hay dos tipos de etnografía:

1. La etnografía "meramente descriptiva", cuyos destinatarios son los de la cultura del etnógrafo.

2. La etnografía "activa", que ha sido encargada por los etnografiados, como "diagnóstico cultural y que es devuelta a la comunidad solicitante, que puede aceptarla si es eficaz en la solución de sus problemas.

La investigación intercultural comprende tres etapas:

a. La etnográfica constituye la primera etapa de la investigación cultural y comprende, a la vez, un trabajo de campo (proceso) y un estudio monográfico (producto). Es una disciplina que estudia y describe la cultura de una comunidad desde la observación participante y desde el análisis de los datos observados.

b. La etnología surge desde la comparación de las diversas aportaciones etnográficas como construcción teórica de la cultura, dentro de una triple síntesis: geográfico-espacial, histórico-temporal y sistemático-estructural.

La Antropología, como lo precisa C. Levi Strauss:

"apunta a un conocimiento global del hombre y abarca el objeto en toda su extensión geográfica e histórica, aspira a un conocimiento aplicables al conjunto del desenvolvimiento del hombre desde los homínidos a las razas modernas y tiende a conclusiones, positivas o negativas, pero válidas para todas las sociedades humanas, desde la gran ciudad moderna hasta la pequeña tribu melanesia". ${ }^{6}$

c. Entonces, vale decir que Etnografía, Etnología y Antropología son tres etapas de la investigación sociocultural. La Antropología nos proporciona un nivel de síntesis, la creación de "modelos o teorías" de conocimiento para comprender las culturas humanas.

Vemos, pues, que la etnografía se constituye en la base empírica del conocimiento antropológico.

5 AGUIRRE, Ángel (ed) (1997). Etnografía. Metodología cualitativa en la investigación sociocultural. México: ALFAOMEGA Grupo Editor, S.A.

6 LÉVI-STRAUSS, Claude (1980). Antropología estructural (1958). Buenos Aires: Eudeba. 


\section{- El "choque cultural"}

Como sostiene Aguirre:

"...no se puede ser antropólogo sino se ha vivenciado al menos dos culturas, sino se ha sufrido "choque" de todo análisis transcultural: saber que existen otras culturas y que todos los elementos culturales son relativos y comparables".?

Cuando un etnógrafo se acerca a "otra cultura" se encuentra inerme y desamparado, pues su cultura no le ayuda a entender. El "choque cultural" tiene dos propósitos fundamentales:

a) Para los etnógrafos, conocer mediante la observación participante la cultura elegida. A partir de esta nueva vivencia cultural, el etnógrafo no solo relativizará su etnocentrismo, sino que su vida se partirá en dos y ya no será más, ni de "aquí" ni de "allí" totalmente.

b) Por el contrario, existe una mirada sucia del turista mercader que compra "sensaciones de choque", emociones duras. Las compra con dinero y no las integra en su vida sino como trofeos de safari. Su mirada etnocéntrica trata a los "otros" como "pobres", "salvajes", "primitivos".

\section{- Desde el etnocentrismo al particularismo}

Es etnocéntrico el que se comporta como si no existiese sino su cultura o como si las "otras culturas" fuesen "inferiores".

Por el contrario, la Etnográfía nos descubre las otras culturas en toda su grandeza y dignidad. Este relativismo contrario al etnocentrismo surgió como una respuesta a la violencia generalizadora del evolucionismo. El relativismo ha puesto de manifiesto la singularidad y particularidad de los procesos culturales. Cada etnia se ha formado en un nicho geográfico concreto y a través de una historia singular; por eso, cada cultura es única e irrepetible, un particularismo histórico.

Si bien es cierto que el etnocentrismo es criticable, sin embargo, no podemos aceptar que cada cultura es única e irrepetible, porque atentaríamos contra posibles regularidades y generalizaciones y poder teorizar. Por eso, la Etnografía nos enseña a conocer otras culturas y compararlas entre sí para encontrar posibles semejanzas y/o diferencias y como punto de partida de hipótesis de trabajo y teorías de desarrollo científico.

\section{- El estudio etnográfico}

Para comenzar, señalo que el estudio etnográfico de una comunidad es un proceso o realización del "trabajo de campo" mediante la "observación participante", durante un tiempo determinado, según sus particularidades culturales y geográfico-espaciales.

Este proceso comprende los siguientes pasos:

a) Demarcación del campo de estudio.

b) Preparación y documentación.

c) Investigación.

d) Conclusión.

El trabajo etnográfico debe ser igualmente aplicable al estudio realizado entre los tuareg, en una comunidad pesquera mediterránea, o en una empresa. Tradicionalmente, los etnógrafos elegían para su trabajo de campo comunidades pequeñas y aisladas. Hoy, la investigación etnográfica empieza a ser predominantemente urbana, y los manuales etnográficos se pueden referir a los colectivos de inmigrantes, a las empresas, a los barrios populares, etc.

7 AGUIRRE, Ángel (ed) (1997). Etnografía. Metodología cualitativa en la investigación sociocultural. México: ALFAOMEGA Grupo Editor, S.A. 
El proceso etnográfico se adapta a las particularidades de la temática a investigarse. No es rígido, sino flexible. Como sabemos, en todo estudio etnográfico se hace imprescindible la documentación bibliográfica y de archivo. Se trata de un trabajo etnohistórico previo para conocer las fuentes de su identidad cultural. Igualmente es necesaria la utilización de las fuentes orales, ya que en todas las comunidades existe una "tradición narrativa".

Es manifiesta la importancia de la transmisión oral en el folklore infantil y en la cultura popular. El etnógrafo debe elegir bien a sus informantes "nativos" que les proporcionan información sobre su cultura. Gran parte del trabajo etnográfico, además del "estar allí", ser observacional, descansa en la aportación de los informantes.

La observación participante nos aporta, a lo largo de la estancia en la comunidad estudiada, el conocimiento "directo" y experiencial de la cultura. A lo largo del trabajo de campo, el etnógrafo es el "principal instrumento" de análisis de la cultura nativa, siendo la observación participante un continuo diálogo intercultural e interpersonal, donde se da un “intercambio" entre las perspectivas "Emic" y "Etic".

Finalmente, hay que preparar la terminación del trabajo y comenzar a elaborar la ruptura, ya que en el trabajo de campo se crean vínculos y lazos afectivos. Una vez terminado el trabajo, conviene recoger y ordenar la información acumulada para permitir su traslado y su utilización posterior en la redacción de la monografía. Es decir, cuando ya se han recogido los datos suficientes para explicar la totalidad de la cultura estudiada y pueda obtenerse, a través de ellos, una visión holística de la misma, de acuerdo con el Proyecto de Investigación estructurado.

\section{- El producto etnográfico}

Terminado el proceso de investigación etnográfica, se analiza el producto etnográfico que comprende diferentes pasos para convertir el trabajo de campo en monografía etnográfica y compararla críticamente con otras.

a) Análisis y organización del material. El análisis del material etnográfico se realiza en una doble dirección: por una parte, el material recogido obliga desde la realidad experiencial (presión "emic"), al etnógrafo a redefinir el proyecto original; por otra parte, este material recibido debe ser "reorganizado, desde la perspectiva científica para ser devuelto como diagnóstico a los nativos o como modelo a los demás etnógrafos (presión "etic").

Hay, pues, como una confrontación entre las dos perspectivas: la perspectiva "naturalista" o "emic", es decir, el dejarse llevar por la estructura y dinámica de la cultura nativa y "transcribirla" fielmente; y la perspectiva del observador o "etic" que reorganiza el discurso para hacerlo inteligible desde sus categorías.

b) En la elección del tipo de monografía intervienen diferentes factores. En primer lugar, puede decirse que cada autor tiene su forma de expresarse, su forma "retórica", como critican los posmodernos, de comunicarnos la experiencia etnográfica.

Ya he señalado que una etnografía puede tener dos destinatarios: por una parte, las monografías deberían ser escritas casi exclusivamente para los nativos (comunidades, empresas, agrupamientos vecinales, etc.), siendo éstos los que deberían encargar los trabajos de campo. Estas monografías serían "diagnósticos" culturales (vg., fusión de empresas, cambio cultural, etc.); y encargaría al etnógrafo un estudio diagnóstico para ser devuelto a la comunidad solicitante, que puede aceptarlo o no, según su eficacia en la solución de los problemas.

Pero, este tipo de "etnografía antigua que debería ser la habitual, es tan escasa como los trabajos de antropología aplicada. 
El segundo destinatario, el habitual entre nosotros, de estas monografías es la comunidad académica y el mundo universitario.

Sólo el día en que nuestros "nativos urbanos" encarguen etnografías para, no solo leerlas y aceptarlas, sino para exigirles eficacia, se habrían acabado todas las discusiones sobre si la Etnografía es o no retórica.

c) La redacción de una monografía ha sido interpretada como relato histórico y criticada por el posmodernismo. Sin embargo, cuando la monografía etnográfica pueda ser leída por los nativos, podrá adornársela con la literatura que se quiera, pero, al final tiene que reflejar la verdad reconocible, aunque esta verdad (como un diagnóstico negativo) llegue a doler.

En suma, hemos visto que la etnografía es el estudio descriptivo de una cultura. Representa el primer paso, la recogida de datos, dentro de la investigación cultural. Invadiendo la frontera que define a la "otra cultura", el etnógrafo recibe un "choque cultural" que lo relativiza, que le destruye su etnocentrismo. Solo si se ha llegado a vivenciar dos culturas, se puede adquirir conocimiento antropológico, porque nos permite percibir su "particular existencia" y comprender que hay "otras" formas de organización de vida, además de la nuestra.

También como he señalado, el estudio etnográfico comprende dos momentos fundamentales: la etnografía como "proceso" y la etnografía como "producto". El primero, corresponde al trabajo de campo, y señalé como momentos más importantes el acceso a la comunidad, el diálogo con los informantes, el registro de datos y la atención flotante. Los estudios etnográficos se sutentan también a través de las biografías, estudio de familias y comunidades, que sumados al marco teórico permiten una visión más clara de la población investigada, otorgando relevancia a los hechos y situaciones de la compleja estructura social de la comunidad.

El producto etnográfico se construye mediante un informe etnográfico o monografía. Lo primero que hace el etnógrafo es "descontextualizarse", alejarse de la cultura observada participativamente para poder objetivarla.

Necesitamos también una etnografía "activa", como he señalado anteriormente, que analice, incluso por encargo la funcionalidad de la cultura de una comunidad, proponga decisiones diagnósticas y resuelva los problemas.

Abogo por este tipo de etnografía activa, aplicada y eficaz, que a nuestro entender, redefina el papel de la antropología, en general, y el de la etnografía, en particular.

Termino este tema sobre etnografía y comparación precisando el carácter descriptivo de la Etnografía que permite conocer la cultura de una comunidad dada debido a que se convivió con ellos, a través de la observación participante y se ha tenido cabal conocimiento de sus instituciones, costumbres, religiosidad y de su cultura en general. Esto es, el producto que presenta la etnografía para la continuación de estudios mayores a través de la comparación y el análisis de las fuentes presentadas; es la materia prima que conduce a la Antropología a la elaboración de una teoría del conocimiento del hombre, su cultura y su entorno.

Comprender el método etnográfico es haber encontrado la "vía regia" para analizar cualitativamente la realidad sociocultural.

- Metodología Etnográfica

\section{Etnografía y Método Científico}

Como he señalado, los antropólogos hacen trabajo de campo, organizan monografías etnográficas, comparan y teorizan. En la medida en que estudia la diversidad sociocultural, la etnografía tiene interés y valor per se, porque no descubre "nuevas formas de organización social, política, religiosa, etc." 
La antropóloga Gonzáles, en 1990, plantea: “Antes y ahora los antropólogos han reflexionado sobre los procedimientos de investigación que permiten penetrar en la diversidad sociocultural y en ocasiones eclosiona una auténtica conciencia crítica. Así se da la nueva etnografía de los años 50 y 60, ó la etnografía posmoderna de la pasada década. Estas etapas suponen una reconsideración de los fundamentos epistemológicos de la etnografía, pero también una sofisticación de los recursos técnicos. Son también, etapas críticas, un estimulo para la construcción de renovadas etnografías". ${ }^{8}$

Propone construir una antropología cuyo propósito sea explicar la diversidad humana desde una perspectiva intercultural y contribuir al desarrollo de una ciencia social de alcance mundial, lo que me parece correcto y necesario. Con una idea de "ciencia" que se ha ido rodeando de todas las reservas extendidas por Kuhn y Feyerabend, reflexiona sobre la posibilidad de formular teorías antropológicas de dominio teóricamente delimitado, susceptibles de ser criticadas y sobre las formas de poner a prueba teorías sobre fenómenos socioculturales, sean estas sobre una cultura determinada o de ámbito intercultural. De ahí su interés en la utilización de materiales etnográficos preexistentes en la contrastación que es el punto de partida.

Esta contribución va directamente encaminada a analizar el uso de informes etnográficos previos en la puesta a prueba de teorías antropológicas dentro de los procedimientos críticos de que disponemos, pero quiere situar estos procedimientos técnicos en su contexto epistemológico y metodológico, entendiendo por "método" no el diseño de una investigación, sino la lógica -las lógicas de la investigación.

\section{- Etnografía y Teoría Antropológica}

Desde el principio, en Antropología se dio la doble hermenéutica, interpretativa y explicativa. La Antropología ha sido siempre en sus descripciones interpretativas, porque los sujetos cuya cultura constituía su objeto de estudio eran básicamente "otros", no inmediatamente inteligibles, a diferencia de la Sociología, que pudo ser más positivista, porque partía de una supuesta familiaridad que parecía permitirle objetivar a los sujetos que investigaba.

En este sentido, no hay una etnografía interpretativa y otra que no lo sea. Todas las monografías etnográficas son interpretativas y se las puede comparar críticamente con otras. Estas formas de relativismo epistemológico no es nueva en Antropología, pero tiende ahora a apoyarse en la sociología del conocimiento, que desarrolla una sociología que tiene que hacerse también antietnocéntrica y cualitativa, porque lo era menos o no lo era.

La Antropología también precisa la necesidad de hablar de antropología científica, para no eludir un conjunto de cuestiones problemáticas con lo cual concuerdo plenamente.

Sobre el método científico, por ejemplo, entendido como un sistema para desarrollar y fundamentar el conocimiento, esto es, como lógica de investigación, formulado en contextos histórico culturales determinados, se le exige certezas a partir de una base empírica firme, que en el caso de la Antropología nos lo proporciona la Etnografía, y conjeturas verificables (Carnap) o refutables (Popper).

Como se puede entender, el énfasis metodológico pasó de los enunciados a las teorías, y es fundamental crear teorías científicas con mayor consistencia empírica etnográfica.

Entiendo que la búsqueda de explicaciones teóricas en antropología puede hacerse en el marco de una cultura, pero considero más adecuado y necesario que las explicaciones teóricas tengan como base empírica etnográfica un conjunto de áreas de estudio e investigación diferentes para compararlas, contrastarlas y explicarlas, y de esa manera formular hipótesis de trabajo y nuevas teorías. Esa es la perspectiva.

8 GONZÁLES, Aurora (1990). Etnografía y método científico. Barcelona. 
En suma, el laboratorio en Antropología, es el trabajo de campo; en su acepción más amplia, aunque no sea este el único laboratorio. Volvamos los ojos a la investigación etnográfica sociocultural, fuente de muchas de las hipótesis y, al mismo tiempo, lugar por excelencia para la contrastación de las teorías antropológicas. El trabajo de campo y la comparación intercultural para someter a crítica nuestras elaboraciones teóricas es el camino de la ciencia y nuestro reto como especialistas en la materia.

\section{Bibliografía}

ARAMBURÚ, SOBREVILLA et al.

1978 Ciencias Sociales en el Perú. Un balance crítico. Lima: Universidad del Pacífíco. Colección de Ensayos.

RODRÍGUEZ PASTOR, Humberto (compilador)

1985 La Antropología en el Perú. Colección de Ensayos. Lima: CONCYTEC. 